\title{
BMJ Open Impact of gestational weight gain and prepregnancy body mass index on the prevalence of large-for-gestational age infants in two cohorts of women with type 1 insulin-dependent diabetes: a cross-sectional population study
}

Ketrell L McWhorter, ${ }^{1,2,3}$ Katherine Bowers, ${ }^{2}$ Lawrence M Dolan, ${ }^{4}$ Ranjan Deka, ${ }^{1}$ Chandra L Jackson, ${ }^{3}$ Jane C Khoury ${ }^{2,4}$

To cite: McWhorter KL, Bowers K, Dolan LM, et al. Impact of gestational weight gain and prepregnancy body mass index on the prevalence of large-for-gestational age infants in two cohorts of women with type 1 insulin-dependent diabetes: a cross-sectional population study. BMJ Open 2018;8:e019617. doi:10.1136/ bmjopen-2017-019617

- Prepublication history and additional material for this paper are available online. To view these files, please visit the journal online (http://dx.doi. org/10.1136/bmjopen-2017019617).

Received 15 September 2017 Revised 17 January 2018 Accepted 12 February 2018

Check for updates

For numbered affiliations see end of article.

Correspondence to Dr Ketrell L McWhorter; ketrell.mcwhorter@nih.gov

\section{ABSTRACT}

Objectives Despite improvements in treatment modalities, large-for-gestational age (LGA) prevalence has remained between $30 \%$ and $40 \%$ among infants of mothers with type 1 insulin-dependent diabetes mellitus (TIDM). Our objective was to estimate LGA prevalence and examine the association between gestational weight gain (GWG) and prepregnancy body mass index (BMI) with LGA among mothers with TIDM.

Design Cross-sectional study.

Setting Regional data in Cincinnati, Ohio, from the Diabetes in Pregnancy Program Project (PPG), a prospective cohort for the period 1978-1993; national data from Consortium on Safe Labor (CSL), a multicentre cross-sectional study for the period 2002-2008.

Participants The study included 333 pregnancies in the PPG and 358 pregnancies in the CSL. Pregnancies delivered prior to 23 weeks' gestation were excluded. Women with TIDM in the PPG were identified according to physician confirmation of ketoacidosis, and/or c-peptide levels, and by International Classification of Diseases, ninth version codes within the CSL. LGA was identified as birth weight $>90$ th percentile according to gestational age, race and sex.

Main outcome measures LGA at birth.

Results Mean \pm SD maternal age at delivery was $26.4 \pm 5.1$ years for PPG women and $27.5 \pm 6.0$ years for CSL women, $p=0.008$. LGA prevalence did not significantly differ between cohorts (PPG: $40.2 \%$ vs CSL: $36.6 \%, p=0.32$ ). More women began pregnancy as overweight in the later cohort (PPG (16.8\%) vs CSL (27.1\%), $p<0.001)$. GWG exceeding Institute of Medicine (IOM) guidelines was higher in the later CSL (56.2\%) vs PPG (42.3\%) cohort, $\mathrm{p}<0.001$. Normal-weight women with GWG within IOM guidelines had a lower LGA prevalence in CSL (PPG: $30.6 \%$ vs CSL: $13.7 \%), p=0.001$.

Conclusions Normal-weight women with GWG within IOM guidelines experienced a lower LGA prevalence, supporting the importance of adherence to IOM guidelines for GWG to reduce LGA. High BMI and GWG may be hindering a reduction in LGA prevalence.

\section{Strengths and limitations of this study}

- We had access to two cohorts of women with type 1 insulin-dependent diabetes mellitus across a 30 -year time period that covered an era of major advancements in insulin treatment and delivery, and emergence of obesity as a prevalent chronic disease, potentially representing opposing risks for delivery of a large-for-gestational age baby.

- The Diabetes in Pregnancy Program Project (PPG) cohort includes frequent, repeated observations of women during pregnancy while the Consortium on Safe Labor (CSL) provides a national, contemporary large-scale database.

- Glucose control was not available in CSL, which precluded comparison between groups.

- The potential differences between local (PPG) and national (CSL) populations include regional variation in diet, methods of treatment, racial composition and geography, which limit the generalisability of our results.

- Despite the importance of nephropathy and retinopathy as indicators of diabetes severity potentially affecting glucose transport, different definitions between the cohorts prevented variable harmonisation, and therefore prevented the adjustment of these factors in our study.

\section{BACKGROUND}

Despite advancements in insulin treatment and delivery for those with type 1 insulin-dependent diabetes mellitus (TIDM), ${ }^{12}$ the prevalence of neonatal large-for-gestational age (LGA) among women in this population remains high. ${ }^{1-5}$ LGA prevalence has remained at $30 \%-40 \%$ among infants of mothers with TIDM. ${ }^{5-7}$ Independently associated maternal risk factors for LGA include maternal age, race/ethnicity, stature, ${ }^{8}$ 
and parity, ${ }^{5-12}$ excessive fetal nutrition ${ }^{13}$ mediated by maternal hyperglycaemia, ${ }^{2}$ excessive gestational weight gain (GWG) ${ }^{5}{ }^{14-16}$ and prepregnancy body mass index (BMI). ${ }^{10141718}$ LGA infants of mothers with diabetes are at increased risk for fetal distress ${ }^{6}$ leading to caesarean section, ${ }^{19}$ and also obesity, ${ }^{20-22}$ insulin resistance (IR), ${ }^{20}$ type 2 diabetes mellitus (T2DM) and cardiovascular compromise ${ }^{2324}$ in adolescence and adulthood.

The steady state of higher perinatal birth weight among offspring of mothers with TIDM, even in the presence of tight glucose control, has promoted studies that emphasise the independent role of both increased rates of prepregnancy $\mathrm{BMI}^{19}$ and excessive $\mathrm{GWG}^{15}$ on neonatal outcome. According to data from NHANES, between 2011 and 2014, nearly 34\% of women aged 20-39 years were obese. ${ }^{25}$ Most recently, among all women who delivered a live infant in 2014, nearly $50 \%$ had a prepregnancy BMI of either overweight $(25.6 \%)$ or obese $(24.8 \%){ }^{25}$

In addition to the trend in increasing prepregnancy BMI, more women are gaining weight in excess of the 2009 Institute of Medicine (IOM) guidelines for GWG. ${ }^{26-28}$ According to the IOM and National Research Council in 'Re-examining the Guidelines', there has been an upward trend in GWG from 1990 to $2005 .{ }^{28}$ Women with TIDM who gain excessive gestational weight have been found to be at even greater risk of LGA, perhaps due to excessive fetal nutrition resulting from increased maternal carbohydrate intake following hypoglycaemic events. ${ }^{15}$ Other studies have suggested IR developing as early as in utero ${ }^{29}$ as a result of overproduction of fetal insulin in response to circulating maternal glucose crossing the placenta. ${ }^{30}$ The fetus then stores this surplus energy as fat and can result in perinatal complications such as LGA. ${ }^{18}$ Given these two trends and the link between the hyperglycaemic intrauterine environment and fetal overnutrition, ${ }^{19} 3132$ women with TIDM belonging to higher BMI subgroups, who exceed IOM guidelines for GWG, may be at the greatest risk of LGA.

In an effort to understand the implications of excessive GWG and prepregnancy BMI within this population, we compared LGA infants observed in the Diabetes in Pregnancy Program Project (PPG), a cohort of women with TIDM going through pregnancy, studied from 1978 to 1993, to those in the Consortium on Safe Labor (CSL), a more contemporary TIDM population delivering between 2002 and 2008. We aimed to determine how prevalence estimates of LGA among infants exposed to maternal TIDM differed between 1978-1993 and 20022008. To identify subgroups who may be at the highest risk for LGA, we also aimed to determine associations between adherence to IOM guidelines for GWG and LGA outcome among mothers with TIDM, across prepregnancy BMI categories. These findings will help interpret the literature on IOM guidelines for GWG in the TIDM population as well as inform future research focusing on reducing LGA births among infants exposed to maternal hyperglycaemic environments.

\section{RESEARCH DESIGN AND METHODS}

\section{Diabetes in PPG}

The PPG study enrolled 303 women with TIDM in a cohort in Cincinnati, Ohio from 1978 to 1993 for a total of 372 pregnancies progressing beyond 23 weeks' gestation. After exclusions, the analytical population included 333 pregnancies. Participants in the PPG were recruited preconceptionally or during the first half of the pregnancy period as part of a programme funded by the National Institutes of Health (NIH) in order to examine the impact of strict glycaemic control during pregnancy on the rate of adverse maternal and neonatal outcomes in mothers with TIDM. The interdisciplinary core of this study involved endocrinologists, perinatologists and neonatologists. TIDM study subjects recruited and enrolled into the programme belonged to White's classification B to RT. ${ }^{33}$ Two levels of glycaemic control were defined to manage diabetes care: subjects enrolling prior to 9 completed weeks of gestation were randomised to strict or customary glycaemic control. A third group included women enrolling after 9 completed weeks' gestation; they were managed according to customary glycaemic control. Fasting blood glucose and $90 \mathrm{~min}$ postprandial glucose targets for strict glycaemic control were: $<100 \mathrm{mg} / \mathrm{dL}$ and $<120 \mathrm{mg} / \mathrm{dL}$, respectively, for customary glycaemic control: $<120 \mathrm{mg} / \mathrm{dL}$ and $<140 \mathrm{mg} /$ $\mathrm{dL}$, respectively. ${ }^{33}$ Extensive gestational and outcome data were collected including weekly weight, blood pressure, insulin requirements, urinalysis and medication use, multiple daily glucose concentrations and detailed delivery and neonatal outcome information.

\section{Consortium on Safe Labor}

The CSL study enrolled 208695 women in a national multicentre observational study from 2002 to 2008 for a total of 228562 deliveries. A total of 594 singleton TIDM pregnancies with delivery at $\geq 23$ weeks' gestation were identified. After exclusions, the analytical population included 358 pregnancies. There were 11 (out of 12) sites represented in the CSL sample of pregnancy complicated by TIDM.

The National Institute of Child Health and Human Development, of the NIH, initiated a retrospective, observational study in a contemporary US obstetric population to re-examine labour progression trends that have long been guided by the Friedman curve. The CSL study included medical records from a population of women from a consortium of 12 US hospitals located across 9 districts of the American College of Obstetricians and Gynecologists and has been described in detail elsewhere. ${ }^{34}$ Briefly, patient electronic medical records were extracted, de-identified and entered into a Data Coordinating database which maintained over 225000 deliveries $\geq 23$ weeks' gestation from 2002 to 2008. Each delivery included International Classification of Diseases, ninth version (ICD-9) codes as well as information related to maternal demographics, maternal weight $(\mathrm{kg})$ and height $(\mathrm{m})$ at admission, prenatal history, pre-eclampsia, blood pressure, reports of uterine and intra-amniotic 
infections, anaesthesia, obstetric trauma, medication, delivery method, infant birth weight, length, Apgar scores at 1 and $5 \mathrm{~min}$, gestational age at delivery and postnatal time spent in the neurointensive care unit. Data received by the Data Coordinating Center from each clinical site were mapped to predefined codes for each variable. Data underwent inquiries, cleaning, recoding and logical checking. In addition, validation studies were performed to ensure electronic medical records accurately represented medical record charts. ${ }^{34}$

Inclusion and exclusion criteria for the current study were identical for each study cohort. Inclusion criteria included TIDM and gestation at 23 completed weeks or later. Exclusion criteria were multiple gestation, fetal anomaly, stillbirth, and missing values for birth weight of the neonate, maternal prepregnancy and delivery weight and maternal height. For women with more than one pregnancy during the study, all pregnancies were included. In addition, no exclusions were made in the CSL based on geographical site.

GWG and prepregnancy BMI were the primary exposures of interest, and LGA was the outcome of interest. Potential confounding maternal characteristics of interest included maternal age at delivery, race, parity and pre-eclampsia. Prepregnancy BMI was additionally treated as a potential modifier of the relationship between GWG and LGA. Institutional Review Board approval was obtained from Cincinnati Children's Hospital Medical Center as well as the University of Cincinnati prior to the secondary analysis of PPG and CSL cohorts.

\section{Statistical analysis}

In two different cohorts, we conducted an analysis on mothers with TIDM who had singleton pregnancies. Women with TIDM in the PPG study were identified according to physician confirmation of ketoacidosis, and/ or c-peptide levels. Within the CSL cohort, ICD-9 codes 250.01, 250.03, 250.21, 250.23, 250.31, 250.33, 250.41, $250.43,250.51,250.53,250.61,250.63$, 250.71, 250.73, $250.81,250.83,250.91,250.93$ were used to identify women with TIDM. To determine LGA classification for each cohort, a McNemar's test of marginal homogeneity was performed comparing Lubchenco curves to both Cincinnati-based reference population growth curves for PPG and medical chart LGA classifications for CSL. LGA was finally defined as birth weight $>90$ th percentile and was classified by gestational age-specific, race-specific and sex-specific curves according to Lubchenco et $a l^{35}$ for the PPG cohort and by the extracted variable from detailed medical chart review for CSL. Prepregnancy BMI was calculated by using self-reported weight prior to pregnancy and height, recorded at the initial visit for women in the PPG and at the labour and delivery admission for women in the CSL. Underweight, normal weight, overweight and obese prepregnancy BMI classifications were defined as: BMI $<18.5 \mathrm{~kg} / \mathrm{m}^{2} ; 18.5 \leq \mathrm{BMI}<25 \mathrm{~kg} /$ $\mathrm{m}^{2}, 25 \leq \mathrm{BMI}<30 \mathrm{~kg} / \mathrm{m}^{2}$ and BMI $\geq 30 \mathrm{~kg} / \mathrm{m}^{2}$, respectively. GWG was defined as weight at admission for delivery minus prepregnancy weight $(\mathrm{kg})$. IOM adherence for GWG was categorised using the prepregnancy BMI-specific 2009 guidelines as under, within (underweight: 12.5$18.0 \mathrm{~kg}$; normal: 11.5-16.0 kg; overweight: $7.0-11.5 \mathrm{~kg}$; obese (all classes): $5.0-9.0 \mathrm{~kg}$ ) or over IOM guidelines. Calculations for recommended weight gain assume a $0.5-2.0 \mathrm{~kg}$ weight gain in the first trimester. ${ }^{28}$ Variables within PPG and CSL were harmonised for comparative analysis. Race was based on self-identification, and was categorised as black, white or other. Due to the small number of obese women in the PPG cohort, overweight and obese BMI categories were combined for analysis. Continuous and categorical variables are represented with mean $( \pm \mathrm{SD})$ and $\mathrm{n}(\%)$, respectively. Maternal characteristics were compared between and within cohorts by LGA status and by adherence to IOM guidelines for GWG (under, within and over) using $\mathrm{X}^{2}$ or Fisher's exact test, and analysis of variance or Wilcoxon rank-sum test, as appropriate. Normality testing for distribution of continuous variables was performed by examining histograms, stem-and-leaf plots and Kolmogorov-Smirnov tests. A site frequency distribution was examined to investigate possible bias in site representation in the CSL sample. Bonferroni was used to adjust for multiple testing. Generalised estimating equations were used to estimate the OR of giving birth to an LGA infant for women exceeding IOM guidelines versus women who adhered to IOM guidelines to account for inherent correlation among women with multiple pregnancies in each study. General linear models were used to examine the relationships between GWG and birth weight. To determine whether IOM adherence varied across BMI categories $\left(18.5 \leq \mathrm{BMI}<25,25 \leq \mathrm{BMI}<30\right.$, BMI $\left.\geq 30 \mathrm{~kg} / \mathrm{m}^{2}\right)$ interaction terms were used to evaluate effect modification. Normalweight women within IOM guidelines for GWG was used as the reference category. Models adjusted for potential confounders, selected a priori as risk factors for GWG and LGA and not on the causal pathway, included age, race, parity, prepregnancy BMI and pre-eclampsia. All tests for significance were two sided and a $p$ value of less than 0.05 was considered statistically significant, appropriately adjusted as necessary. Statistical analyses were completed using SAS software V.9.4.

\section{RESULTS}

Table 1 shows maternal characteristics and neonatal outcomes in each cohort. Mean age at delivery was significantly higher for women in the CSL $(27.5 \pm 6.0)$ than for women in the PPG $(26.4 \pm 5.1), \mathrm{p}=0.008$. There was a higher proportion of black women in the CSL (19.3\%) than in the PPG $(14.1 \%)$. The CSL had a significantly greater proportion of overweight/obese women $(51.4 \%)$ than the PPG $(20.7 \%), \mathrm{p}<0.001$. More women exceeded IOM guidelines for GWG in the CSL (56.2\%) than in the PPG (42.3\%), $\mathrm{p}<0.001$, with overweight/obese women accounting for $58.7 \%$ and $41.1 \%$ of all women who exceeded guidelines, respectively (online supplementary table $\mathrm{S} 1$ ). 
Table 1 Maternal characteristics and neonatal outcomes in PPG (1978-1993) and CSL (2002-2008) cohorts

\begin{tabular}{|c|c|c|c|}
\hline & PPG & CSL & \\
\hline Maternal characteristics & $\mathrm{n}=333$ & $\mathrm{n}=358$ & $P$ values \\
\hline Maternal age at delivery (years) & $26.4 \pm 5.1$ & $27.5 \pm 6.0$ & 0.008 \\
\hline Married, yes* & $224(67.3)$ & $217(60.6)$ & 0.01 \\
\hline Race & & & $<0.001$ \\
\hline White & $282(84.7)$ & $225(62.8)$ & \\
\hline Black & $47(14.1)$ & $69(19.3)$ & \\
\hline Other & $4(1.2)$ & $64(17.9)$ & \\
\hline Nulliparous, yes & $166(49.9)$ & $183(51.1)$ & 0.74 \\
\hline Prepregnancy BMI (kg/m²) & $23.0 \pm 3.4$ & $26.9 \pm 6.3$ & $<0.001$ \\
\hline Prepregnancy BMI category & & & $<0.001$ \\
\hline Underweight $\left(\mathrm{BMI}<18.5 \mathrm{~kg} / \mathrm{m}^{2}\right)$ & $11(3.3)$ & $6(1.7)$ & \\
\hline Normal $\left(18.5 \mathrm{~kg} / \mathrm{m}^{2} \leq \mathrm{BMl}<25.0 \mathrm{~kg} / \mathrm{m}^{2}\right)$ & $253(76.0)$ & $168(46.9)$ & \\
\hline Overweight $\left(25.0 \mathrm{~kg} / \mathrm{m}^{2} \leq \mathrm{BMl}<30.0 \mathrm{~kg} / \mathrm{m}^{2}\right)$ & $56(16.8)$ & $97(27.1)$ & \\
\hline Obese $\left(\mathrm{BMI} \geq 30.0 \mathrm{~kg} / \mathrm{m}^{2}\right)$ & $13(3.9)$ & $87(24.3)$ & \\
\hline Prepregnancy overweight/obese & $69(20.7)$ & $184(51.4)$ & $<0.001$ \\
\hline Gestational weight gain $(\mathrm{kg})$ & $14.4 \pm 5.6$ & $14.5 \pm 7.4$ & 0.77 \\
\hline \multicolumn{4}{|l|}{ IOM guidelines } \\
\hline Under & $74(22.2)$ & $62(17.3)$ & $<0.001$ \\
\hline Within & $118(35.5)$ & $95(26.5)$ & \\
\hline Over & $141(42.3)$ & 201 (56.2) & \\
\hline Pre-eclampsia, yes & $50(15.0)$ & $55(15.4)$ & 0.90 \\
\hline Previous caesarean section, yes ${ }^{*}$ & $105(31.6)$ & $86(24.0)$ & 0.08 \\
\hline Caesarean section, yes & $233(70.0)$ & $239(66.8)$ & 0.36 \\
\hline \multicolumn{4}{|l|}{ Preterm delivery, yes } \\
\hline Delivery prior to 34 weeks & $33(9.9)$ & $48(13.4)$ & 0.15 \\
\hline Delivery prior to 37 weeks & $114(34.2)$ & $152(42.6)$ & 0.03 \\
\hline \multicolumn{4}{|l|}{ Neonatal outcomes $\dagger$} \\
\hline Male & $186(56.2)$ & $193(53.9)$ & 0.60 \\
\hline Respiratory distress during labour & $37(11.1)$ & 45 (12.8) & 0.49 \\
\hline Gestational age (weeks) & $37.0 \pm 2.4$ & $36.1 \pm 2.7$ & $<0.001$ \\
\hline Apgar less than 7 (@5 min) & $59(17.7)$ & $23(6.4)$ & \\
\hline
\end{tabular}

Mean \pm SD are shown for all continuous variables and $\mathrm{n}(\%)$ are shown for categorical variables.

*PPG: marital status missing for 11 women; CSL, previous caesarean section missing for 20 women.

†Neonatal outcomes exclude stillbirths and neonatal deaths.

BMI, body mass index; CSL, Consortium on Safe Labor; IOM, Institute of Medicine; PPG, Pregnancy Program Project.

There was no significant difference in caesarean section rate between the CSL $(66.8 \%)$ and PPG $(70.0 \%)$, $\mathrm{p}=0.36$. Women were more likely to deliver at less than 37 weeks' in the CSL $(42.6 \%)$ than in the PPG $(34.2 \%)$, $\mathrm{p}=0.03$.

While we observed no difference in overall LGA prevalence between cohorts (CSL: $36.6 \%$ vs PPG: $40.2 \%$, $\mathrm{p}=0.32$ ), table 2 shows a lower prevalence of LGA among women in CSL compared with PPG (13.7\% vs $30.6 \%)$ who were normal weight and gained within IOM guidelines.

Normal-weight women still have the highest proportion of LGA infants in both the CSL and PPG cohorts (48.1\% vs $73.9 \%$ ) (see table 3 ). The prevalence of LGA was higher in the later CSL cohort compared to the PPG cohort among both overweight (29.8\% vs $17.2 \%)$ and obese (21.4\% vs $6.0 \%)$ participants. Normal-weight women in the CSL, on average, gained $2.4 \mathrm{~kg}$ more over gestation than normal-weight women in the PPG. In contrast, overweight women in the $\mathrm{CSL}$, on average, gained $2.6 \mathrm{~kg}$ less than overweight women in the PPG (online supplementary table S2).

Table 4 shows separate associations between prepregnancy BMI and GWG with odds of LGA for all women in each cohort. Entering pregnancy with higher BMI did not appear to be an independent predictor of LGA in either group. 
Table 2 Large-for-gestational age (LGA) prevalence within each BMI and IOM adherence subgroup for women in PPG (19781993) and CSL (2002-2008) cohorts

\begin{tabular}{|c|c|c|c|c|c|c|c|c|}
\hline \multirow{2}{*}{$\begin{array}{l}\text { IOM } \\
\text { adherence }\end{array}$} & \multirow{2}{*}{ Prepregnancy BMI } & \multicolumn{3}{|c|}{ PPG } & \multicolumn{3}{|l|}{ CSL } & \multirow[b]{2}{*}{$P$ values } \\
\hline & & $\mathbf{N}$ & LGA & $\%$ LGA* $^{*}$ & $\mathbf{N}$ & LGA & $\%$ LGA* & \\
\hline \multicolumn{9}{|l|}{ Under } \\
\hline & Underweight & 4 & 1 & 0.7 & 2 & 1 & 0.8 & 0.99 \\
\hline & Normal & 67 & 20 & 14.9 & 33 & 8 & 6.1 & 0.02 \\
\hline & Overweight/obese & 3 & 1 & 0.7 & 27 & 6 & 4.6 & 0.06 \\
\hline \multicolumn{9}{|l|}{ Within } \\
\hline & Underweight & 7 & 3 & 2.2 & 3 & 0 & 0.0 & 0.25 \\
\hline & Normal & 103 & 41 & 30.6 & 53 & 18 & 13.7 & 0.001 \\
\hline & Overweight/obese & 8 & 0 & 0.0 & 39 & 12 & 9.2 & 0.0003 \\
\hline \multicolumn{9}{|l|}{ Over } \\
\hline & Underweight & 0 & 0 & 0.0 & 1 & 0 & 0.0 & - \\
\hline & Normal & 83 & 38 & 28.4 & 82 & 37 & 28.2 & 0.98 \\
\hline & Overweight/obese & 58 & 30 & 22.4 & 118 & 49 & 37.4 & 0.008 \\
\hline Total & & 333 & 134 & 40.2 & 358 & 131 & 36.6 & 0.32 \\
\hline
\end{tabular}

BMI was defined as: underweight $\left(B M I<18.5 \mathrm{~kg} / \mathrm{m}^{2}\right)$; normal $\left(18.5 \mathrm{~kg} / \mathrm{m}^{2} \leq \mathrm{BMl}<25.0 \mathrm{~kg} / \mathrm{m}^{2}\right)$; overweight $\left(25.0 \mathrm{~kg} / \mathrm{m}^{2} \leq \mathrm{BMl}<30.0 \mathrm{~kg} / \mathrm{m}^{2}\right) ;$ obese $\left(\mathrm{BMI} \geq 30.0 \mathrm{~kg} / \mathrm{m}^{2}\right)$.

*\% LGA for each IOM guideline adherence and prepregnancy BMI category is presented as proportions of total LGA infants for each category.

BMI, body mass index; CSL, Consortium on Safe Labor; IOM, Institute of Medicine; PPG, Diabetes in Pregnancy Program Project.

When considering all BMI groups collectively, exceeding IOM guidelines for GWG versus remaining within IOM guidelines was not a significant predictor of increased risk for LGA in either cohort. The OR adjusted for age for mothers who exceeded IOM guidelines compared with those who remained within guidelines was similar for women in the CSL (OR 1.62, 95\% CI 0.97 to $2.72, \mathrm{p}=0.07$ ) compared with mothers in the PPG (OR $1.57,95 \% \mathrm{CI}$ 0.92 to $2.65, p=0.10$ ). There was also no significant difference in average total GWG between the groups, 14.5 \pm 7.4 for CSL and 14.4 \pm 5.6 for PPG ( $\mathrm{p}=0.77$ ). There remained no significant increase in oddsof LGA after further adjustments for covariates and prepregnancy BMI for either group.

In the CSL, normal-weight women who exceeded IOM guidelines (OR 2.14, 95\% CI 1.17 to $3.91, \mathrm{p}=0.01$ ) and overweight women who exceeded IOM guidelines (OR $2.35,95 \%$ CI 1.26 to $4.40, \mathrm{p}=0.01$ ) had increased odds of LGA after adjusting for age when compared with the normal-weight women who did not exceed IOM guidelines, as shown in table 5 .

After adjusting for other risk factors, the combined effect of overweight and exceeding IOM guidelines remained, with an increase in odds of LGA (OR 2.25, 95\% CI 1.18 to 4.28, $\mathrm{p}=0.01$ ) compared with the reference group. The increased odds for LGA in normal-weight women who exceed IOM guidelines was slightly attenuated (OR 1.83, $95 \%$ CI 0.99 to $3.40, p=0.06$ ). Similar results were shown for overweight/obese women in the PPG who exceeded IOM guidelines. There was an increase in odds of LGA for these women in both models adjusted for age only (OR 2.04,
95\% CI 1.05 to $3.97, \mathrm{p}=0.03$ ) and fully adjusted models (OR 2.12, 95\% CI 1.11 to 4.04, $\mathrm{p}=0.02$ ) compared with normal-weight women who remain within IOM guidelines.

\section{DISCUSSION}

Although delivery of LGA infants in the TIDM population has been examined in several epidemiological studies, few studies have examined LGA prevalence over time. In this analysis of GWG, prepregnancy BMI and LGA infant births among mothers with TIDM, we identified several important overall and GWG-specific and BMI-specific patterns. Our crude results suggest no change in overall LGA prevalence over a 30 -year period. However, the proportion of infants born LGA to women of normal weight who adhered to GWG guidelines was lower by $17 \%$. This reduction appeared to be offset by a $15.0 \%$ increase in LGA prevalence among overweight/ obese women who exceeded IOM guidelines.

Persson et at 2009 showed that in a contemporary population of women with TIDM, obstetric and perinatal complications, particularly higher birth weight remain markedly higher than the general population. Similarly, the results of our study demonstrate that high weight for gestational age remains a frequent outcome in pregnancies complicated by TIDM, despite advancements throughout the years in glucose management and insulin treatment and delivery. Overall, our study showed LGA prevalence, for both groups, was markedly higher than the general population, despite observing reductions within select BMI subgroups. 
Table 3 Maternal characteristics of women in PPG (1978-1993) and CSL (2002-2008) cohorts by LGA classification

\begin{tabular}{|c|c|c|c|c|c|c|}
\hline \multirow[b]{2}{*}{ Characteristic } & \multicolumn{3}{|l|}{ PPG } & \multicolumn{3}{|l|}{ CSL } \\
\hline & $\begin{array}{l}\text { LGA } \\
\text { Lubchenco } \\
\text { et al }\end{array}$ & Non-LGA & $P$ values & $\begin{array}{l}\text { LGA } \\
\text { chart }\end{array}$ & Non-LGA & $P$ values \\
\hline $\mathrm{n}(\%)$ & $134(40.2)$ & $199(59.8)$ & & $131(36.6)$ & $227(63.4)$ & \\
\hline Maternal age at delivery, years & $26.5 \pm 4.9$ & $26.4 \pm 5.2$ & 0.83 & $27.5 \pm 6.1$ & $27.6 \pm 6.0$ & 0.92 \\
\hline Married, yes & $94(70.1)$ & $130(65.3)$ & 0.08 & $87(66.4)$ & $130(57.3)$ & 0.09 \\
\hline Race & & & 0.36 & & & 0.001 \\
\hline White & $118(88.1)$ & $164(82.4)$ & & $97(74.1)$ & $128(56.4)$ & \\
\hline Black & $15(11.2)$ & $32(16.1)$ & & $13(9.9)$ & $56(24.7)$ & \\
\hline Other & $1(0.78)$ & $3(1.5)$ & & $21(16.0)$ & $43(18.9)$ & \\
\hline Nulliparous, yes & $59(44.0)$ & $107(53.8)$ & 0.08 & $60(45.8)$ & $123(54.2)$ & 0.13 \\
\hline Prepregnancy BMI $\left(\mathrm{kg} / \mathrm{m}^{2}\right)$ & $23.3 \pm 3.6$ & $22.7 \pm 3.2$ & 0.9 & $26.7 \pm 5.8$ & $26.9 \pm 6.5$ & 0.77 \\
\hline Prepregnancy BMI category & & & 0.45 & & & 0.5 \\
\hline Underweight $\left(\mathrm{BMI}<18.5 \mathrm{~kg} / \mathrm{m}^{2}\right)$ & $4(3.0)$ & $7(3.5)$ & & $1(0.76)$ & $5(2.2)$ & \\
\hline Normal $\left(18.5 \mathrm{~kg} / \mathrm{m}^{2} \leq \mathrm{BMl}<25.0 \mathrm{~kg} / \mathrm{m}^{2}\right)$ & 99 (73.9) & $154(77.4)$ & & $63(48.1)$ & $105(46.3)$ & \\
\hline Overweight $\left(25.0 \mathrm{~kg} / \mathrm{m}^{2} \leq \mathrm{BMl}<30.0 \mathrm{~kg} / \mathrm{m}^{2}\right)$ & $23(17.2)$ & $33(16.6)$ & & $39(29.8)$ & $58(25.6)$ & \\
\hline Obese $\left(\mathrm{BMI} \geq 30.0 \mathrm{~kg} / \mathrm{m}^{2}\right)$ & $8(6.0)$ & $5(2.5)$ & & $28(21.4)$ & $59(26.0)$ & \\
\hline Prepregnancy overweight/obese & $31(23.1)$ & $38(19.1)$ & 0.38 & $67(51.2)$ & $117(51.5)$ & 0.94 \\
\hline Gestational weight gain (kg) & $15.7 \pm 5.4$ & $13.5 \pm 5.7$ & $<0.0001$ & $16.3 \pm 7.2$ & $13.5 \pm 7.3$ & 0.0004 \\
\hline IOM guidelines & & & 0.02 & & & 0.01 \\
\hline Under & $22(16.4)$ & $52(26.1)$ & & $15(11.5)$ & $47(20.7)$ & \\
\hline Within & $44(32.8)$ & $74(37.2)$ & & $30(22.9)$ & $65(28.6)$ & \\
\hline Over & $68(50.8)$ & $73(36.7)$ & & $86(65.7)$ & $115(50.7)$ & \\
\hline Pre-eclampsia, yes & $11(8.2)$ & $39(19.6)$ & 0.004 & $19(14.5)$ & $36(15.9)$ & 0.73 \\
\hline Previous caesarean section, yes & $45(33.8)$ & $60(30.2)$ & 0.48 & $38(29.9)$ & $48(22.8)$ & 0.14 \\
\hline Caesarean section, yes & $97(72.4)$ & $136(68.3)$ & 0.43 & $91(69.5)$ & $148(65.2)$ & 0.41 \\
\hline \multicolumn{7}{|l|}{ Preterm delivery } \\
\hline Delivery prior to 34 weeks & $6(4.5)$ & $27(13.6)$ & 0.007 & $11(8.4)$ & $37(16.3)$ & 0.03 \\
\hline Delivery prior to 37 weeks & $38(28.4)$ & $76(38.2)$ & 0.06 & $55(42.0)$ & $97(42.7)$ & 0.89 \\
\hline \multicolumn{7}{|l|}{ Neonatal outcomes } \\
\hline Male & $81(61.4)$ & $105(52.8)$ & 0.12 & $71(54.2)$ & $122(54.2)$ & 1.0 \\
\hline Respiratory distress during labour & $11(8.2)$ & $26(13.1)$ & 0.17 & $16(12.5)$ & $29(13.0)$ & 0.89 \\
\hline Gestational age, weeks & $37.5 \pm 1.9$ & $36.6 \pm 2.7$ & 0.001 & $36.3 \pm 2.2$ & $36.0 \pm 3.0$ & 0.22 \\
\hline Apgar less than 7 (@5min) & $20(14.9)$ & $39(19.6)$ & 0.27 & $9(6.87)$ & $14(6.2)$ & 0.79 \\
\hline
\end{tabular}

Mean \pm SD are shown for all continuous variables and $n(\%)$ are shown for categorical variables.

LGA was defined as infants with a birth weight $>90$ th percentile, adjusted for age, sex and race.

Neonatal outcomes exclude stillbirths and neonatal deaths.

BMI, body mass index; CSL, Consortium on Safe Labor; IOM, Institute of Medicine; LGA, large-for-gestational age; PPG, Diabetes in

Pregnancy Program Project.

Historically, obesity has been associated with T2DM. However, the TIDM population has shown a significant increase in women entering pregnancy as overweight and obese. There was a marked increase in the proportion of overweight/obese women in the CSL compared with the PPG $(51.4 \%$ vs $20.7 \%)$. Women in the CSL belonging to the overweight/obese subgroup accounted for a greater proportion of those who exceeded IOM guidelines (58.7\%) compared with women in the PPG (41.1\%).
Overweight/obese women who exceeded IOM guidelines showed a $15.0 \%(p=0.01)$ increase in LGA over time. Our results confirm previous studies that have linked maternal overweight, ${ }^{19}{ }^{31} \mathrm{GWG}^{36}$ and adverse birth outcomes in the TIDM population. Despite the improvement, this subgroup remains at the highest risk of delivering an LGA infant compared with normal-weight women who adhered to IOM guidelines. Interestingly, despite a lower average GWG for women with higher BMI in the CSL 
Table 4 Association between abnormal prepregnancy BMI and unrecommended gestational weight gain compared with normal-weight participants within IOM adherence guidelines among PPG (1978-1993) and CSL (2002-2008) study cohorts

\begin{tabular}{|c|c|c|c|}
\hline & Model I & Model II & Model III \\
\hline & OR (95\% Cl) & OR (95\% Cl) & OR (95\% Cl) \\
\hline \multicolumn{4}{|l|}{ PPG } \\
\hline Prepregnancy BMI & & & - \\
\hline Normal/underweight & 1.00 (reference) & 1.00 (reference) & - \\
\hline Overweight/obese & 1.28 (0.70 to 2.32$)$ & 1.44 (0.79 to 2.63$)$ & - \\
\hline \multicolumn{4}{|l|}{ Gestational weight gain } \\
\hline Under & 0.71 (0.39 to 1.31$)$ & $0.76(0.41$ to 1.41$)$ & $0.76(0.41$ to 1.42$)$ \\
\hline Within & 1.00 (reference) & 1.00 (reference) & 1.00 (reference) \\
\hline Over & 1.57 (0.92 to 2.65$)$ & 1.55 (0.90 to 2.67$)$ & $1.53(0.86$ to 2.71$)$ \\
\hline \multicolumn{4}{|l|}{ CSL } \\
\hline Prepregnancy BMI & & & - \\
\hline Underweight & 0.33 (0.04 to 2.92) & 0.38 (0.03 to 4.21$)$ & - \\
\hline Normal & 1.00 (reference) & 1.00 (reference) & - \\
\hline Overweight & $1.12(0.67$ to 1.87$)$ & 1.32 (0.77 to 2.26$)$ & - \\
\hline Obese & 0.79 (0.46 to 1.36$)$ & 1.04 (0.58 to 1.86$)$ & - \\
\hline \multicolumn{4}{|l|}{ Gestational weight gain } \\
\hline Under & 0.69 (0.33 to 1.43$)$ & 0.75 (0.35 to 1.60$)$ & $0.73(0.34$ to 1.58$)$ \\
\hline Within & 1.00 (reference) & 1.00 (reference) & 1.00 (reference) \\
\hline Over & 1.62 (0.97 to 2.72$)$ & 1.54 (0.91 to 2.63) & $1.46(0.84$ to 2.52$)$ \\
\hline
\end{tabular}

BMI was defined as: underweight $\left(\mathrm{BMI}<18.5 \mathrm{~kg} / \mathrm{m}^{2}\right)$; normal $\left(18.5 \mathrm{~kg} / \mathrm{m}^{2} \leq \mathrm{BMl}<25.0 \mathrm{~kg} / \mathrm{m}^{2}\right)$; overweight $\left(25.0 \mathrm{~kg} / \mathrm{m}^{2} \leq \mathrm{BMl}<30.0 \mathrm{~kg} / \mathrm{m}^{2}\right) ;$ obese $\left(\mathrm{BMI} \geq 30.0 \mathrm{~kg} / \mathrm{m}^{2}\right)$.

Model I: adjusted for age.

Model II: adjusted for model I+maternal race, parity, pre-eclampsia.

Model III: adjusted for model II+prepregnancy BMI.

BMI, body mass index; CSL, Consortium on Safe Labor; IOM, Institute of Medicine; PPG, Diabetes in Pregnancy Program Project.

compared with women in the PPG, women with overweight and obesity remained in excess of IOM guidelines for GWG. On average, overweight and obese CSL women gained $2.6 \mathrm{~kg}$ less and $0.30 \mathrm{~kg}$ more, respectively, over total gestation than overweight and obese women in the PPG. These results suggest that women in the PPG with higher BMI far exceeded IOM guidelines. The reduction in average GWG for overweight and obese women could help explain the lowered LGA prevalence over time in this subgroup, $41.2 \%$ in the CSL compared with $51.7 \%$ in the PPG. Previous studies in the literature have shown the effect of excessive GWG on risk of LGA, independent of BMI. ${ }^{14-16}{ }^{37}$ However, the results of our study did not show BMI and adherence to IOM guidelines as independent predictors of LGA. Women who were overweight (or obese for PPG) and who exceeded GWG guidelines were at a greater than twofold increase risk of delivering an LGA infant (CSL (OR 2.25, 95\% CI 1.18 to 4.28), PPG (OR 2.12, 95\% CI 1.11 to 4.04 )), compared with women who were normal weight and with GWG within IOM guidelines.

The results of our study point to need of future research that includes additional parameters to consider when establishing appropriate GWG guidelines specific to this population, such as age at onset of diabetes (or duration), prepregnancy glucose control and diabetes severity on entering pregnancy. Although in a gestational diabetes (GDM) population, Bowers et $a l^{88}$ were also able to show racial variation in the joint effects of prepregnancy obesity, GWG and GDM on birth weight. Women with TIDM who are planning pregnancies are urged to achieve optimal weight and clinically acceptable glucose control prior to pregnancy. For women in this population with unplanned pregnancies, future research is needed that examines more longitudinal studies that include regular monitoring of glucose and insulin dosage throughout pregnancy, as well as caloric intake. GWG is of key concern, and gestational timing of weight gain may also play a role in increased risk of LGA infants. Studies have demonstrated that first-trimester GWG showed the strongest effect on adverse maternal, fetal and childhood outcomes, including increased neonatal adiposity. ${ }^{39}$ All of these factors should be considered when designing studies that seek to establish new GWG guidelines specific to this population.

This study has several limitations. Our analysis was unable to include a comparison of glucose control between groups, indicated by measures of haemoglobin A1c 
Table 5 Adjusted ORs $(95 \% \mathrm{Cl})$ for LGA by abnormal prepregnancy BMl and unrecommended gestational weight gain compared with normal-weight participants within IOM adherence guidelines among PPG (1978-1993) and CSL (2002-2008) cohorts

\begin{tabular}{|c|c|c|c|c|c|c|}
\hline \multirow[b]{2}{*}{ IOM adherence } & \multirow[b]{2}{*}{ Prepregnancy BMI } & \multirow[b]{2}{*}{$\mathbf{n}$} & \multirow{2}{*}{$\begin{array}{l}\text { Model I } \\
\text { OR (95\% Cl) }\end{array}$} & \multirow[b]{2}{*}{$P$ values } & \multirow{2}{*}{$\begin{array}{l}\text { Model II } \\
\text { OR }(95 \% \mathrm{Cl})\end{array}$} & \multirow[b]{2}{*}{$P$ values } \\
\hline & & & & & & \\
\hline \multicolumn{7}{|l|}{ PPG } \\
\hline \multirow[t]{2}{*}{ Within } & Normal/underweight & 110 & 1.00 (reference) & & 1.00 (reference) & \\
\hline & Overweight/obese & 8 & - & & - & \\
\hline \multirow[t]{2}{*}{ Over } & Normal/underweight & 83 & 1.61 (0.93 to 2.80$)$ & 0.09 & 1.48 (0.83 to 2.64$)$ & 0.18 \\
\hline & Overweight/obese & 58 & 2.04 (1.05 to 3.97 ) & 0.03 & 2.12 (1.11 to 4.04$)$ & 0.02 \\
\hline \multicolumn{7}{|l|}{ CSL } \\
\hline \multirow[t]{3}{*}{ Within } & Normal & 56 & 1.00 (reference) & & 1.00 (reference) & \\
\hline & Overweight & 15 & 0.38 (0.08 to 1.81$)$ & 0.23 & 0.53 (0.10 to 2.73$)$ & 0.45 \\
\hline & Obese & 23 & 1.86 (0.75 to 4.60$)$ & 0.18 & 1.99 (0.79 to 5.01$)$ & 0.15 \\
\hline \multirow[t]{3}{*}{ Over } & Normal & 82 & 2.14 (1.17 to 3.91$)$ & 0.01 & 1.83 (0.99 to 3.40$)$ & 0.06 \\
\hline & Overweight & 70 & 2.35 (1.26 to 4.40$)$ & 0.01 & 2.25 (1.18 to 4.28$)$ & 0.01 \\
\hline & Obese & 49 & 1.26 (0.61 to 2.59$)$ & 0.53 & $1.49(0.70$ to 3.19$)$ & 0.30 \\
\hline
\end{tabular}

BMI was defined as: underweight $\left(\mathrm{BMl}<18.5 \mathrm{~kg} / \mathrm{m}^{2}\right)$; normal $\left(18.5 \mathrm{~kg} / \mathrm{m}^{2} \leq \mathrm{BMl}<25.0 \mathrm{~kg} / \mathrm{m}^{2}\right)$; overweight $\left(25.0 \mathrm{~kg} / \mathrm{m}^{2} \leq \mathrm{BMl}<30.0 \mathrm{~kg} / \mathrm{m}^{2}\right) ;$ obese $\left(\mathrm{BMl} \geq 30.0 \mathrm{~kg} / \mathrm{m}^{2}\right)$.

Insufficient LGA infants of overweight/obese women who remained within IOM guidelines to make LGA OR determination.

Model I: adjusted for age.

Model II: adjusted for model I+maternal race, parity, pre-eclampsia.

BMI, body mass index; CSL, Consortium on Safe Labor; IOM, Institute of Medicine; LGA, large-for-gestational age; PPG, Diabetes in

Pregnancy Program Project.

(HbA1c), as these data were not available for CSL participants. Although Secher et al showed higher GWG was associated with LGA outcomes, independent of glucose control, ${ }^{15}$ these measurements could potentially account for the reduction in LGA prevalence among normalweight women who adhered to IOM guidelines in our study. Second, women with TIDM, when compared with women with T2DM, often have higher HbA1c throughout pregnancy due to higher diabetes duration accompanied with greater variations in glycaemic control. ${ }^{40}$ We did not have access to diabetes duration for women in the CSL. However, it is plausible that diabetes duration was similar for both groups as there was no significant difference in mean maternal age at delivery between the groups for women with LGA infants across all levels of IOM adherence, data not shown. Further, our study compared women with TIDM from a local population to women in a nationally representative population. The differences between the populations, which include regional differences in diet, methods of treatment, access to quality healthcare, racial composition and geography limit the generalisability of our results. However, this study serves as an important start for assessing impact of policy changes on perinatal outcomes like LGA over time. Our sample size for overweight and obese women who remain within IOM guidelines for PPG limited our power to robustly test effect modification, and thus no comparisons across time could be made between groups. However, we were able to examine the role of prepregnancy BMI as an effect modifier in the contemporary CSL cohort. In addition, prepregnancy BMI was determined, in part, by self-reported prepregnancy weight in both cohorts, yielding our calculation of prepregnancy BMI subject to recall bias. The ICD-9 codes that were used to identify women in the CSL with TIDM have not been validated in this study. However, according to Zhang et $a l^{34}$ validation studies were conducted for four key outcomes, including method of delivery, gestational age $\geq 34$ and $\geq 37$ weeks and clinical diagnosis of shoulder dystocia, common in LGA deliveries. Most variables that were reviewed were highly accurate, indicating information provided in the validation studies was reliable and likely generalisable to the entire database. Lastly, despite the importance of nephropathy and retinopathy as indicators of diabetes severity, potentially affecting glucose transport, differing definitions between cohorts prevented variable harmonisation and, therefore, prohibited the adjustment of these factors in our study. Prevalence of nephropathy according to each group's definition was $18.9 \%$ for PPG and $7.8 \%$ for CSL.

Despite these limitations, important strengths exist and this study extends beyond prior studies in several important areas. Our study compared two cohorts of women across a time period wherein major advancements have been made in the treatment of TIDM while simultaneously obesity has become a prevalent chronic diseaserepresenting opposing risks for LGA. Each data set is comprehensive and has unique strengths. For instance, the PPG cohort includes frequent, repeated observations of women during pregnancy, while the CSL is large and contemporary. 
In conclusion, while overall LGA prevalence appears to have remained relatively unchanged over time, based on these two cohorts, normal-weight women with TIDM who adhered to IOM guidelines have experienced a reduction in LGA prevalence. Women in a more recent TIDM population are starting the pregnancy period with significantly higher proportions of overweight and obesity than in previous years. Entering pregnancy as overweight while exceeding IOM guidelines for GWG places women in this population at the highest risk of LGA. This study demonstrates the importance of strict adherence to IOM guidelines for GWG, particularly for women who enter pregnancy as overweight, in order to address reduction of LGA rates in the TIDM population.

\section{Author affiliations}

${ }^{1}$ Department of Environmental Health, College of Medicine, University of Cincinnati, Cincinnati, Ohio, USA

${ }^{2}$ Division of Biostatistics and Epidemiology, Cincinnati Children's Hospital Medical Center, Cincinnati, Ohio, USA

${ }^{3}$ Epidemiology Branch, Department of Health and Human Services, National Institute of Environmental Health Sciences, National Institutes of Health, Research Triangle Park, North Carolina, USA

${ }^{4}$ Division of Endocrinology, Cincinnati Children's Hospital Medical Center, Cincinnati, Ohio, USA

Contributor Study concept and design: KLM, JCK; acquisition of data: JCK; statistical analysis: KLM; interpretation of data: KLM, JCK, KB, CLJ, RD, LMD; drafting of the manuscript: KLM; critical revision of the manuscript for important intellectual content: KLM, JCK, KB, CLJ, RD, LMD; administrative, technical and material support: CLJ, JCK. All authors approved of the version of the manuscript to be published. Institutions involved in the consortium, in alphabetical order: Baystate Medical Center, Springfield, MA; Cedars-Sinai Medical Center Burnes Allen Research Center, Los Angeles, CA; Christiana Care Health System, Newark, DE; EMMES Corporation (data-coordinating center), Rockville, MD; Georgetown University Hospital, MedStar Health, Washington, DC; Indiana University Clarian Health, Indianapolis, IN; Intermountain Healthcare and University of Utah, Salt Lake City, UT; Maimonides Medical Center, Brooklyn, NY; MetroHealth Medical Center, Cleveland, OH; Summa Health System, Akron City Hospital, Akron, $\mathrm{OH}$; University of Illinois at Chicago, Chicago, IL; University of Miami, Miami, FL; and University of Texas Science Center at Houston, Houston, TX.

Funding This work was supported, in part, by the University of Cincinnati, Molecular Epidemiology in Children's Environmental Health Training Grant (T32ES10957), NIH grant Diabetes in Pregnancy Program Project Grant (HD11725), the Consortium on Safe Labor was funded by the Eunice Kennedy Shriver Intramural Research Program of the NICHD (Contract No. HHSN267200603425C) and the Intramural Research Training Program of the National Institute for Environmental Health Sciences (ES16003). This work was also funded, in part, by the Intramural Program at the NIH, National Institute of Environmental Health Sciences (Z1AES103325-01).

Competing interests None declared.

\section{Patient consent Obtained.}

Ethics approval IRB approval was obtained from Cincinnati Children's Hospital Medical Center as well as the University of Cincinnati prior to the secondary analysis of the Diabetes in Pregnancy Program Project (PPG) and the Consortium on Safe Labor (CLS) data.

Provenance and peer review Not commissioned; externally peer reviewed.

Data sharing statement No additional data are available.

Open Access This is an Open Access article distributed in accordance with the Creative Commons Attribution Non Commercial (CC BY-NC 4.0) license, which permits others to distribute, remix, adapt, build upon this work non-commercially, and license their derivative works on different terms, provided the original work is properly cited and the use is non-commercial. See: http://creativecommons.org/ licenses/by-nc/4.0/ (c) Article author(s) (or their employer(s) unless otherwise stated in the text of the article) 2018. All rights reserved. No commercial use is permitted unless otherwise expressly granted.

\section{REFERENCES}

1. Evers IM, de Valk HW, Mol BW, et al. Macrosomia despite good glycaemic control in Type I diabetic pregnancy; results of a nationwide study in The Netherlands. Diabetologia 2002;45:1484-9.

2. Catalano PM, Hauguel-De Mouzon S. Is it time to revisit the Pedersen hypothesis in the face of the obesity epidemic? Am J Obstet Gynecol 2011;204:479-87.

3. Persson B, Hanson U. Fetal size at birth in relation to quality of blood glucose control in pregnancies complicated by pregestational diabetes mellitus. Br J Obstet Gynaecol 1996;103:427-33.

4. Kerssen A, de Valk HW, Visser GH. Increased second trimester maternal glucose levels are related to extremely large-for-gestationalage infants in women with type 1 diabetes. Diabetes Care 2007;30:1069-74.

5. Scifres CM, Feghali MN, Althouse AD, et al. Effect of excess gestational weight gain on pregnancy outcomes in women with type 1 diabetes. Obstet Gynecol 2014;123:1295-302.

6. Persson M, Norman M, Hanson U. Obstetric and perinatal outcomes in type 1 diabetic pregnancies: a large, population-based study. Diabetes Care 2009;32:2005-9.

7. Kim SY, Kotelchuck M, Wilson HG, et al. Prevalence of adverse pregnancy outcomes, by maternal diabetes status at first and second deliveries, Massachusetts, 1998-2007. Prev Chronic Dis 2015;12:E218.

8. Sjaarda LA, Albert PS, Mumford SL, et al. Customized large-forgestational-age birthweight at term and the association with adverse perinatal outcomes. Am J Obstet Gynecol 2014;210:63.e1-63.e11.

9. Stotland NE, Caughey AB, Breed EM, et al. Risk factors and obstetric complications associated with macrosomia. Int J Gynaecol Obstet 2004;87:220-6.

10. Surkan PJ, Hsieh CC, Johansson AL, et al. Reasons for increasing trends in large for gestational age births. Obstet Gynecol 2004;104:720-6.

11. Cundy T, Gamble G, Manuel A, et al. Determinants of birth-weight in women with established and gestational diabetes. Aust N Z J Obstet Gynaecol 1993;33:249-54.

12. Wilcox MA, Chang AM, Johnson IR. The effects of parity on birthweight using successive pregnancies. Acta Obstet Gynecol Scand 1996;75:459-63.

13. Heerwagen MJ, Miller MR, Barbour LA, et al. Maternal obesity and fetal metabolic programming: a fertile epigenetic soil. Am J Physiol Regul Integr Comp Physiol 2010;299:R711-22.

14. Starling AP, Brinton JT, Glueck DH, et al. Associations of maternal $\mathrm{BMI}$ and gestational weight gain with neonatal adiposity in the Healthy Start study. Am J Clin Nutr 2015;101:302-9.

15. Secher AL, Parellada CB, Ringholm L, et al. Higher gestational weight gain is associated with increasing offspring birth weight independent of maternal glycemic control in women with type 1 diabetes. Diabetes Care 2014;37:2677-84.

16. Kim SY, Sharma AJ, Sappenfield W, et al. Preventing large birth size in women with preexisting diabetes mellitus: The benefit of appropriate gestational weight gain. Prev Med 2016;91:164-8.

17. Ehrenberg HM, Mercer BM, Catalano PM. The influence of obesity and diabetes on the prevalence of macrosomia. Am J Obstet Gynecol 2004;191:964-8.

18. Sacks DA, Liu Al, Wolde-Tsadik G, et al. What proportion of birth weight is attributable to maternal glucose among infants of diabetic women? Am J Obstet Gynecol 2006;194:501-7.

19. Morrens A, Verhaeghe J, Vanhole C, et al. Risk factors for large-forgestational age infants in pregnant women with type 1 diabetes. BMC Pregnancy Childbirth 2016;16:162.

20. Hill DJ, Prapavessis H, Shoemaker JK, et al. Relationship between birth weight and metabolic status in obese adolescents. ISRN Obes 2013;2013:1-8.

21. Schellong K, Schulz S, Harder T, et al. Birth weight and long-term overweight risk: systematic review and a meta-analysis including 643,902 persons from 66 studies and 26 countries globally. PLoS One 2012;7:e47776.

22. Hediger ML, Overpeck MD, McGlynn A, et al. Growth and fatness at three to six years of age of children born small- or large-forgestational age. Pediatrics 1999;104:e33.

23. Zhang Z, Kris-Etherton PM, Hartman TJ. Birth weight and risk factors for cardiovascular disease and type 2 diabetes in US children and 
adolescents: 10 year results from NHANES. Matern Child Health $J$ 2014;18:1423-32.

24. Boney CM, Verma A, Tucker R, et al. Metabolic syndrome in childhood: association with birth weight, maternal obesity, and gestational diabetes mellitus. Pediatrics 2005;115:e290-6.

25. Branum AM, Kirmeyer SE, Gregory EC. Prepregnancy body mass index by maternal characteristics and state: data from the birth certificate, 2014. Natl Vital Stat Rep 2016;65:1-11.

26. Chu SY, Callaghan WM, Bish CL, et al. Gestational weight gain by body mass index among US women delivering live births, 20042005: fueling future obesity. Am J Obstet Gynecol 2009;200:271. e1-271.e7.

27. Mamun AA, O'Callaghan M, Callaway L, et al. Associations of gestational weight gain with offspring body mass index and blood pressure at 21 years of age: evidence from a birth cohort study. Circulation 2009;119:1720-7.

28. Institute of M, National Research Council Committee to Reexamine IOMPWG. The National Academies Collection: Reports funded by National Institutes of Health. In: Rasmussen KM, Yaktine AL, eds. Weight gain during pregnancy: reexamining the guidelines. Washington (DC): National Academies Press (US) National Academy of Sciences, 2009.

29. Catalano PM, Presley L, Minium J, et al. Fetuses of obese mothers develop insulin resistance in utero. Diabetes Care 2009;32:1076-80.

30. Arshad R, Karim N, Ara Hasan J. Effects of insulin on placental, fetal and maternal outcomes in gestational diabetes mellitus. Pak J Med Sci 2014;30:240-4.

31. Persson M, Pasupathy D, Hanson U, et al. Pre-pregnancy body mass index and the risk of adverse outcome in type 1 diabetic pregnancies: a population-based cohort study. BMJ Open 2012;2:e000601.
32. Rosenberg TJ, Garbers S, Lipkind H, et al. Maternal obesity and diabetes as risk factors for adverse pregnancy outcomes: differences among $4 \mathrm{racial} / \mathrm{ethnic}$ groups. Am J Public Health 2005;95:1545-51.

33. Miodovnik M, Mimouni F, Dignan PS, et al. Major malformations in infants of IDDM women. Vasculopathy and early first-trimester poor glycemic control. Diabetes Care 1988;11:713-8.

34. Zhang J, Troendle J, Reddy UM, et al. Contemporary cesarean delivery practice in the United States. Am J Obstet Gynecol 2010;203:326.e1-326.e10.

35. Lubchenco LO, Hansman C, Dressler M, et al. Intrauterine growth as estimated from liveborn birth-weight data at 24 to 42 weeks of gestation. Pediatrics 1963;32:793-800.

36. Egan AM, Dennedy MC, Al-Ramli W, et al. ATLANTIC-DIP: excessive gestational weight gain and pregnancy outcomes in women with gestational or pregestational diabetes mellitus. J Clin Endocrinol Metab 2014;99:212-9.

37. Nohr EA, Vaeth M, Baker JL, et al. Combined associations of prepregnancy body mass index and gestational weight gain with the outcome of pregnancy. Am J Clin Nutr 2008;87:1750-9.

38. Bowers K, Laughon SK, Kiely M, et al. Gestational diabetes, pre-pregnancy obesity and pregnancy weight gain in relation to excess fetal growth: variations by race/ethnicity. Diabetologia 2013;56:1263-71.

39. Josefson JL, Simons H, Zeiss DM, et al. Excessive gestational weight gain in the first trimester among women with normal glucose tolerance and resulting neonatal adiposity. J Perinatol 2016;36:1034-8.

40. Balsells M, García-Patterson A, Gich I, et al. Maternal and fetal outcome in women with type 2 versus type 1 diabetes mellitus: a systematic review and metaanalysis. J Clin Endocrinol Metab 2009;94:4284-91. 